\title{
Negative Social Experiences of University and College Students
}

\author{
Paul F. Tremblay ${ }^{1,2,3}$, Roma Harris ${ }^{2,3}$, Helene Berman ${ }^{2,3}$, Barb MacQuarrie ${ }^{3}$, Gail \\ E. Hutchinson ${ }^{2,3}$, Mary Ann Smith ${ }^{4,3}$, Susan Braley ${ }^{4,3}$, Jennifer Jelley ${ }^{1}$, Kristen \\ Dearlove $^{2}$ \\ ${ }^{1}$ Centre for Addiction and Mental Health, ${ }^{2}$ The University of Western Ontario, \\ ${ }^{3}$ Centre for Research and Education on Violence Against Women and Children, \\ ${ }^{4}$ Fanshawe College
}

\begin{abstract}
In this article we investigate Canadian university and college students' interpersonal conflicts and exposure to abuse and violence during their postsecondary studies and assess the emotional, social, and academic impact of these experiences. Our findings, based on a sample 1174 university and college students in Southwestern Ontario, revealed that although most of the incidents reported were verbal in nature and had relatively little emotional or academic impact, a small proportion of students reported experiencing serious violent incidents including sexual assault or rape, and these incidents have had a significant impact on their lives. Female students living on their own reported greater impact of negative social experiences than those who were living in college or university residences. In addition, students who reported conflicts involving institutional policies or rules, including what they perceived to be unfair workloads or grading practices, indicated that such experiences had a negative impact on their academic performance. We discuss these findings in the context of maintaining safe, healthy climates on university and college campuses.
\end{abstract}

\section{RÉSUMÉ}

Dans cet article, nous étudions les conflits interpersonnels et l'exposition à l'abus et à la violence des étudiantes et étudiants canadiens des niveaux collégial et universitaire au cours de leurs études postsecondaires, ainsi 
que l'impact émotionnel, social et académique de ces expériences. Les résultats sont basés sur un échantillon de 1174 étudiantes et étudiants du sud-ouest de l'Ontario. Les résultats démontrent que, bien que la plupart des incidents signalés soient des conflits de nature verbale qui ont eu peu d'impact émotionnel ou académique, une petite proportion d'étudiantes et d'étudiants ont quand même signalé des incidents violents, y compris l'agression sexuelle et le viol, et ces expériences ont eu un impact significatif sur leur qualité de vie. Les étudiantes vivant seules ont signalé un plus grand impact que celles vivant en résidence au collège ou à l'université. Les étudiantes et étudiants qui ont signalé des expériences reliées aux politiques institutionnelles et aux règles d'évaluation telles que des charges de travail et des évaluations perçues comme inéquitables ont indiqué que ces expériences ont eu un impact négatif sur leur rendement académique. Nous discutons de ces résultats dans le contexte des efforts visant à maintenir un climat sain de sécurité dans les universités et les collèges.

Echoing the horrific events at Montreal's École Polytechnique, the shootings at Virginia Tech, Northern Illinois University, and Dawson College have once more brought to the fore questions about the safety of university and college campuses. Although tragic events bring the problem into public scrutiny and typically elicit reactions of shock, outrage, and urgent calls for action, research findings suggest that various forms of violence and harassment are a common part of everyday life for many students in Canada and the United States.

A number of studies have explored specific forms of violence experienced by college and university students, such as alcohol-related assaults (e.g., Adlaf, Demers, \& Gliksman, 2005; Wechsler, Lee, Kuo, \& Lee, 2000), sexual harassment, sexual violence, and violence in dating relationships (e.g., Aosved \& Long, 2005; DeKeseredy \& Kelly, 1993; Fisher, Cullen, \& Turner, 2000; Jones, 2000). For instance, in a sample of 433 college students from Buffalo, New York, 29\% of males and $17 \%$ of females had been the targets of physical aggression and $20 \%$ of males and $12 \%$ of females reported initiating an act of aggression in the previous year (Leonard, Quigley, \& Collins, 2002). In another study involving 961 students at a medium-size university in a rural region of the Northeast United States (Luckey, 1999), 30\% of the participants reported that they had been the victims of at least one incident of violence during the previous academic year. These incidents included robbery, assault, sexual victimization, verbal harassment, bias-related violence, domestic violence, dating violence, and hazing. Nine percent of the female respondents were victims of sexual violence consisting of unwanted kissing or petting, unwanted sexual intercourse, or other sexual activity including physically forced or threatened intercourse. In a more recent study among 935 female undergraduates from a southeastern state university in the United States, $36 \%$ of the African American women and $26 \%$ of the White women in the sample had experienced unwanted sexual contact since their university enrolment (Gross, Winslett, Roberts, \& Gohm, 
2006). The sexual aggressors in these situations were known to the women in all but $2 \%$ of the incidents.

In a survey of Canadian campuses, Adlaf et al. (2005) described a number of alcohol-related harms resulting from other students' drinking, including serious arguments or quarrels (17\%), being pushed or assaulted (10\%) and sexual harassment (10\%). Students who resided on campus or off campus without family members were at a significantly greater risk of experiencing these harms than those who were living with their families, off campus. In a study assessing the experiences of physical aggression in the previous year of 2,647 university students at six universities in Canada, 30\% of male and 22\% of female students reported at least one incident (Tremblay, Graham, \& Wells, 2008).

The psychological, social, and health-related effects of different forms of interpersonal conflict in college or university populations have received relatively limited attention, although Mellin (2004) reported that "relational victimization" is associated with depression among college students. However, we do know from studies with other populations that exposure to interpersonal violence and abuse has a negative impact on learning. For example, children who witness violence in their homes do not reach the same level of academic achievement as other children, and they also experience higher levels of depression and anxiety (e.g., Shonk \& Ciccetti, 2001). Moreover, as adult learners, women who are abused by their intimate partners have difficulty engaging in classroom learning (Horsman, 1999), are more distracted by fear for their own and their children's safety (Brush, 2000), and have more trouble concentrating than do women who are not abused (Raphael, 1996). A recent study assessing the impact of uncivil behaviour among university students found that incivility was associated with psychological distress, low satisfaction. and disengagement from university and low academic achievement (Barker Caza \& Cortina, 2007). The study also revealed that the relation between incivility and distress was mediated by perceptions of injustice and ostracism.

The present study had three objectives. The first was to describe university and college students' experiences of harassment, aggression. and violence during their post secondary education. Given the conceptual overlap between harassment, aggression, and violence, and a general lack of agreement in the literature on the boundaries of these concepts, we set out to survey a broad and inclusive category of interpersonal experiences that we labelled "negative social experiences." These experiences include "low-intensity" deviant behaviours that fall under the category of incivility and include acts such as insults and condescending remarks (Barker Caza \& Cortina, 2007). The second objective was to assess the emotional, social and academic impact of these experiences and to determine how impact varied in relation to type of experience, gender of the respondent and of the opponent, and a number of demographic variables. The third objective was to investigate the influence of the various types of negative experiences on the academic work of students. 


\section{Method}

\section{Recruitment and Sample}

In January 2005, 4,995 full-time undergraduate and graduate students at a large university and 2,500 students at a community college in Southwestern Ontario were sent an email message inviting them to participate in an online study. Their email addresses were randomly sampled from a list of all full-time student addresses provided by the Registrars from each institution. The invitation provided a general description of the study as well as a link and a password to access the study website and the consent form. Participants were entered in a draw for one of three cash prizes of $\$ 300$ each. Three reminder email messages were sent to the college sample, and two were sent to the university sample at approximately two-week intervals. A total of 674 university and 500 college students (total = 1,174 ) responded to the survey for an overall response rate of $15.7 \%$.

\section{Survey Questionnaire}

A multidisciplinary team of researchers developed the questionnaire used in the study. A pilot study was conducted with small groups of students to develop, test, and refine the questions. The resulting questionnaire includes a combination of closed- and open-ended questions. The open-ended format was used to allow respondents to provide a general description of negative social interactions they had experienced. Questions were also included to elicit more in-depth specific information about participants' most significant negative social experience, as well as close-ended questions and rating scales that addressed the psychological and academic impact of the incident, reporting of the incident, sources of assistance, and the perceived effectiveness of the services provided. The questionnaire also requested information about students' sex, age, academic year, school or faculty of registration, housing arrangements, language proficiency, ethnoracial background, disabilities, sexual orientation, and identification with religious, spiritual, ethnic, cultural, political and ideological groups.

Negative social experiences. Students were asked to describe any negative social experiences that occurred since their enrolment at college or university. In describing such events, they were advised that "For each experience, we would like to find out about what happened, how often this happened, why you think it happened and anything else you would like to tell us about this experience." Five categories of negative experience were listed:

1. Verbal experiences (e.g., insults, threats, intimidation, humiliation, coercion, offensive conversations directed at you);

2. Physical (e.g., grabbing, pushing, pulling, slapping, punching, unnecessary force used in sporting activities);

3. Sexual (e.g., inappropriate sexual remarks, offensive jokes or dialogue, displays of sexual material, inappropriate touching, demanding sexual favours in return for something, and sexual assault); 
4. Indirect - meaning that you did not have face-to-face contact with the offender (e.g., being the subject of malicious rumours, receiving malicious email messages, having something stolen from you);

5. Other experiences (any other experience not covered in the previous categories).

Impact of negative experiences. Of the experiences they described, the respondents were asked to identify one that had the greatest negative impact on them and they were then asked a number of questions about that experience, including the number and sex of offender(s), whether the offender was part of the university/college community, the relationship between respondent and offender, the location of the experience, the frequency of occurrence, views about why the negative experience occurred, whether and to whom the respondent reported the incident, and the effectiveness of any assistance they received. Using 5-point Likert rating scales, the respondents were also asked to indicate the extent to which the experience they described made them feel (1) upset, (2) angry, (3) afraid, or (4) numb, detached, distant or disconnected from day-today life; as well as the extent to which the experience had a negative impact on their (5) academic work, (6) self-confidence or self-esteem, (7) relationships with friends or family, (8) overall health and well-being, and (9) the extent to which they blamed themselves for the experience. A confirmatory factor analysis revealed that it was appropriate to combine these nine items into one total impact scale $(\alpha=.88)$.

\section{Classifying Negative Social Experiences}

The general categories of experiences, namely verbal, physical, sexual, indirect, and others, were used to help students recall and organize their comments about these events. However, a more specific and precise classification of these experiences was developed by the researchers over several iterations by examining participants' responses, by adding more specific categories of experiences as needed, and by referring to other classification studies (e.g., Harris, M. B., 1992, Graham, Tremblay, Wells, Pernanen, Purcell, \& Jelley, 2006). Three coders used the detailed coding system to classify all the incidents reported by the students. The scheme is presented in Table 1. One of the coders was the project coordinator who has extensive experience coding observational data of aggressive incidents. In addition, two undergraduate nursing students were trained to code the incidents; one coded the incidents reported by the college students, and the other coded the incidents reported by the university students. The coders achieved a reasonably high level of consistency in applying the coding system (the agreement index between the project coordinator and the students was $86.2 \%$; Kappa coefficient $=0.77$ ). When disagreement occurred, a compromise code was assigned. The most significant negative social experiences were also coded using the same classification table by the research coordinator and by a third-year psychology student. The agreement index and inter-rater reliability index (Kappa) were 78.7\% and 0.76 respectively. A compromise code assigned 
by the principal investigator was used in cases where the raters did not agree. When a respondent's description included more than one type of behaviour, the most severe behaviour was selected.

\section{RESULTS}

Of the 1,174 students (72.9\% women) who completed the questionnaire, 710 respondents (64.9\% women and $48.1 \%$ men) reported at least one negative social experience. Among them, they described a total of 1,296 such experiences. In describing these results, we focus on the 614 students who described their most significant negative social experience. The mean age of this group was 22.13 years $(S D=4.9)$ and the majority of these students were women $(78.7 \%)$. Table 1 presents the distribution of the most significant negative social experiences reported by category, from the women and men in this group. As shown in Table 1, the majority of these experiences fell in the mild verbal, gossip/jokes, and severe verbal categories.

\section{Total Impact}

Impact by category. Although many students reported that their experiences had a relatively mild impact, as is shown in Figure 1, this was not the case for those who reported sexual assaults $(M=3.96)$ or for those who chose to describe events that "happened earlier" $(M=3.24)$. With regard to the latter, although the students had been asked to describe experiences that occurred while enrolled in college or university, a few chose to describe earlier events, including sexual assaults, childhood abuse, being disowned, or forced to leave their homes. Such events clearly had a significant and lasting impact on the students who reported them. Although the overall numbers of severe incidents were relatively low, the potential for long-term harm from such incidents is evident in the words of one female student who described a rape that occurred while she was living in residence.

The most negative experience I have had at university... was when I lived in residence last year. I had gone out to the bar one night with a bunch of friends. When I returned to rez [sic] I was quite intoxicated and went to watch a movie with one of my male friends who had accompanied me to the bar. I passed out in his room and woke up because I was being anally raped. Obviously this was the most serious and negative incident for me. It happened because he was also drunk and decided to take advantage of me. I chose not to do anything about it because at the time I felt that it was my fault because I had chosen to go watch a movie with him and I honestly felt absolutely humiliated. I wish now that I had done something about it as it is something that I will never forget. I also now do not like to be touched even by my boyfriend anywhere around my very lower back, bum, and the back of my upper thighs. 
Implicit in these words is the idea that the "victim" was in some sense responsible for the assault and was therefore not entitled to take action against her perpetrator. Also evident is the suffering that continues long after the violent episode occurred.

Significant differences in total impact scores were found between categories of negative experiences based on a one-way analysis of variance, $F(18,567)$ $=7.20, p<.01$. Posthoc tests of means (Tukey HSD) revealed that the "sexual assault/rape" category of incidents had a significantly higher total mean impact than all other categories except the category "happened earlier" which in turn had a higher mean impact than that of several other categories, such as mild physical, horseplay, and body language. ${ }^{1}$ With respect to seemingly milder forms of harassment, several comments from respondents revealed a tendency to minimize the occurrence and the effects of these incidences. As one female participant stated, "I didn't think any of them were too serious. I think it's just a part of life that men will look at a woman's body." Similarly, the comment from another participant suggests that derogatory verbal comments ought not be taken seriously. "Nothing has been large. My college experience has been positive all around. Most negative I could have to say being insults that I've overheard about me." The idea that insults were a mildly annoying but inevitable part of university and college life was expressed repeatedly.

Sex differences in impact. The overall impact of negative social experiences was higher for the women $(M=2.29, S D=0.87)$ than for the men $(M=2.07, S D=$ $0.79), t(602)=2.55, p<.01$. It seems reasonable that such differences would occur partly because the men and women reported experiencing different types of incidents; for example, only female respondents reported that they had been sexually assaulted. To assess whether the male and female respondents were differently affected by types of incidents they had each experienced, tests were performed on categories of negative experiences for which there were at least five male and female respondents. These included the following categories of negative experiences: mild verbal, gossip/jokes, severe verbal, severe physical, theft, policy, and vague description. Significant sex differences in impact were found only in the severe physical category, $t(32)=3.06, p<.01$, with a higher impact score for women $(M=2.74, S D=1.02)$ than men $(M=1.89, S D$ $=0.60$ ).

Sex of the offenders. In the majority of cases, respondents reported that the negative experiences involved only one offender. In some cases however, more than one offender was reported, and the offenders included one or more males, one or more females, or a combination of both. Male and female participants reported similar rates of conflicts with a combination of male and female opponents (7.9\% for males and $8.6 \%$ for females). If we exclude the category containing a combination of male and female opponents, then the proportion of female respondents who reported a conflict with one or more male opponents was $66.2 \%$, and the proportion of male respondents who reported a conflict with one or more male opponents was $75.9 \%$. These proportions were significantly different, $\chi^{2}(1)=3.92$, 


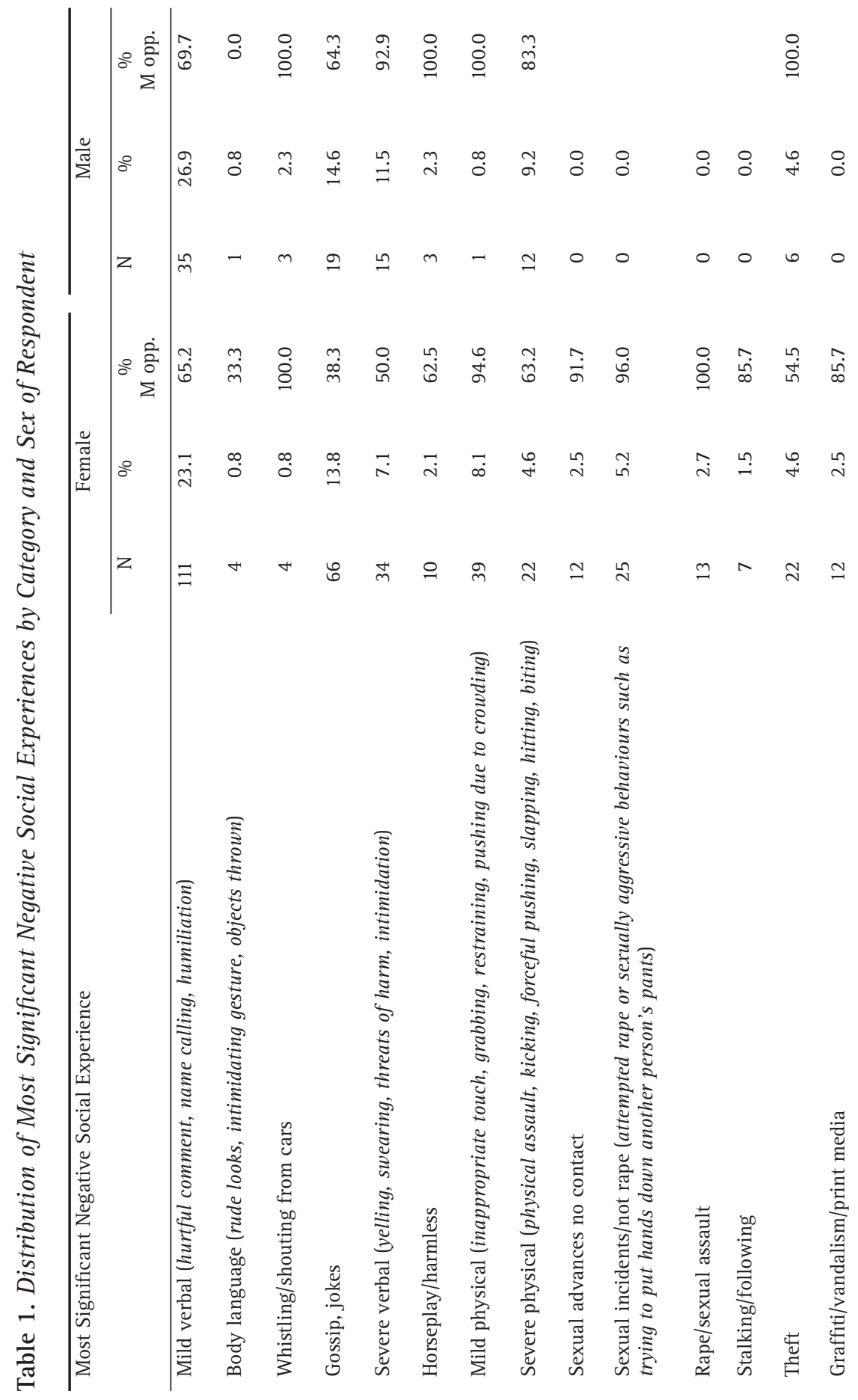




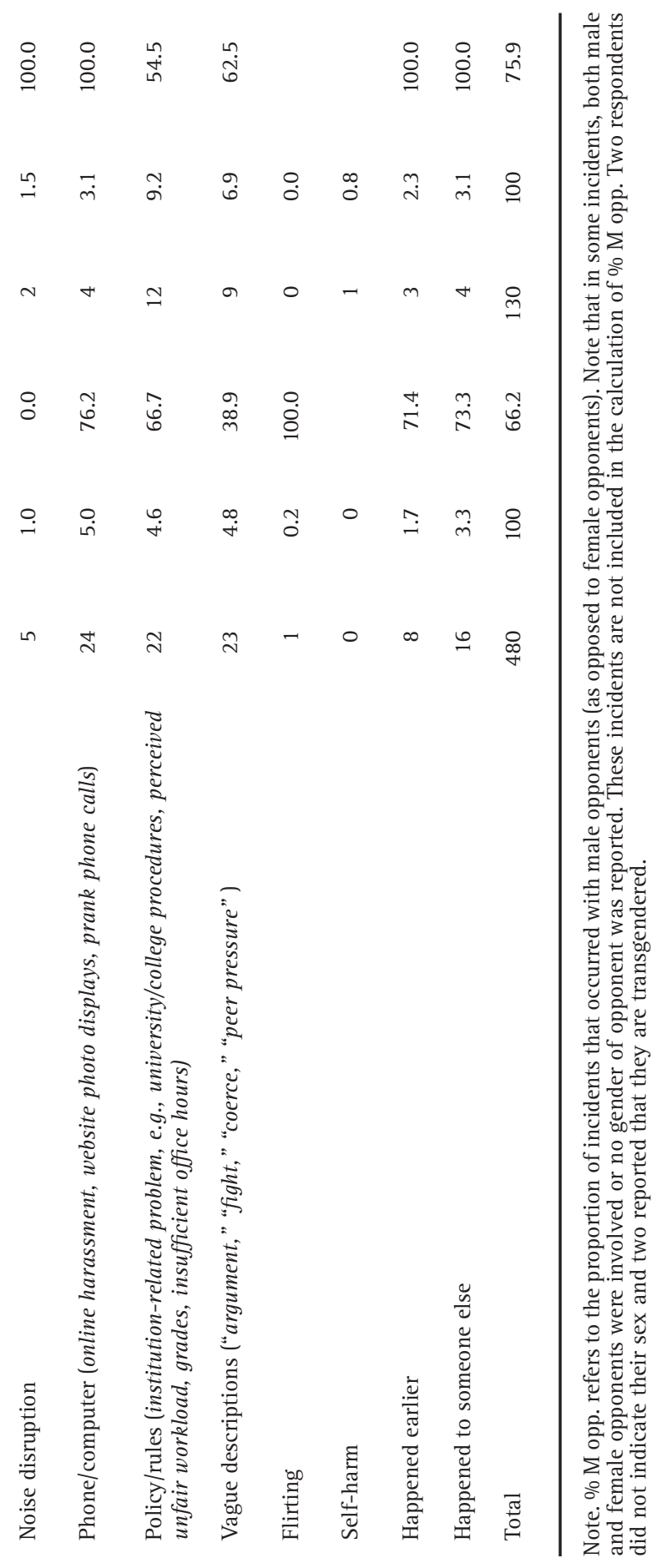


Figure 1 . Total impact mean by category of negative social experience.

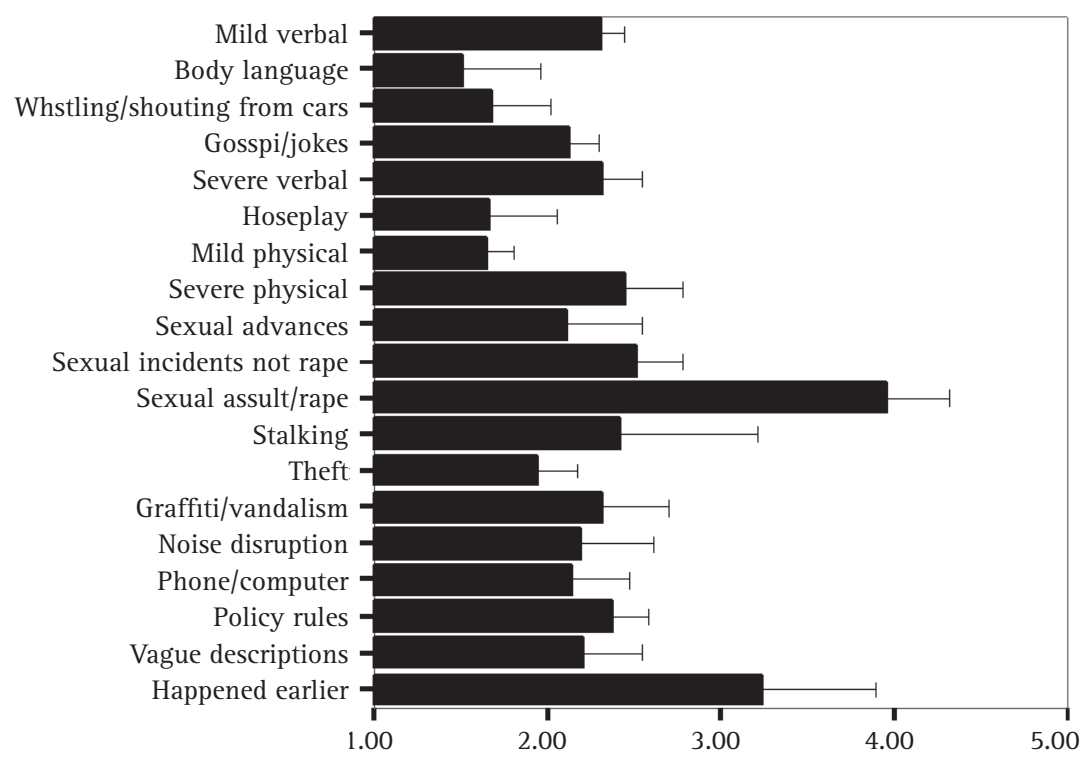

Error bars show the 95th percent confidence intervals. $1=$ no impact; $2=$ little impact; $3=$ moderate impact; $4=$ large impact; $5=$ very large impact.

$\mathrm{p}<.05$. Table 1 also shows the proportions of conflicts that occurred with male opponents by sex of the respondents and category of negative incidents. Within these categories, women report higher proportions of incidents occurring with male opponents than with female opponents except in the categories of gossip and jokes, body language, and noise disruption where a larger proportion of the events occur with female opponents and in the category of severe verbal incidents where the proportions of male and female opponents are equal.

A two-way ANOVA investigating the influence of sex of participant by sex of offender (male only, female only, combination of males and females) on impact scores revealed higher scores when the offender was female $(M=2.37)$ or a combination of males and females $(M=2.40)$ than when the offender was male $(M=2.11), F(2,570)=4.25, p<.05$. Further inspection of this result suggests that although the interaction between sex of the participant by sex of the offender was not significant, the group of male participants who reported male opponents had the lowest mean $(M=1.96)$ and accounts partly for the higher impact mean associated with female offenders.

Living arrangements. Students were asked whether they lived in: (1) a university/college residence, (2) an apartment/room/house 'by myself', (3) at home with parents, (4) a house or apartment with at least one roommate, (5) a house or apartment with spouse/partner, or (6) other. Upon inspection of the reported 
living arrangements in the 'other' category, a new category labelled "living with children" was formed and consisted of only female students. To control for possible sex differences, a two-way ANOVA of impact scores was conducted with living arrangements (leaving out the "living with children" category) and sex of respondent as the independent variables. No significant effects were found. Since only female students reported "living with children," we also conducted a one-way ANOVA on types of residence for female students only which resulted in significant differences in the total impact scores, $F(5,464)=2.44, p<.05$. The mean impact scores were 2.04 (university/college residence), 2.54 (by myself), 2.21 (home with parents), 2.31 (with at least one roommate), 2.33 (with spouse or partner), and 2.63 (with children). Posthoc tests revealed that the category "by myself" resulted in significantly higher total impact scores than did the category "university/college residence."

College and university differences. Significantly more respondents in the university sample (68.1\%) reported negative social experiences than did those from the college sample $(50.2 \%), \chi^{2}(1)=38.48, p<.01$. The proportions of different types of negative experiences were compared for respondents from the two institutions. The only significant difference found was that college students reported a higher proportion of policy/rule incidents (9.5\%) than university students $(3.5 \%), \chi^{2}(1)=9.70, p<.01 .^{3}$ A two-way ANOVA with institution (college vs. university) and sex of respondent as the independent variables revealed no significant differences between the institutions in total impact scores, $F(1,600)$ $=2.02, n s$. As a result of these overall similarities between institutions, we combined the data from both groups of students.

Ethnoracial differences. The ethnoracial distribution of participants who reported their most significant negative social experience was as follows: 78.2\% White, 3.6\% Chinese, 3.6\% Multiracial, 2.6\% Arab/West Asian, 2.6\% South Asian, 1.8\% Aboriginal, 1.8\% Black, 1.2\% Latin American, and 4.6\% 0ther. A two-way ANOVA with ethnoracial group (White vs. All Other) and sex as the independent variables revealed a significant ethnoracial effect on the total impact scores, $F(1,596)=10.42, p<.01$, where the mean impact score for White respondents $(M=2.09)$ was lower than for the All Other group $(M=2.39)$. This result may have been due in part to groups experiencing different types of negative social experiences. This possibility was investigated by comparing the distribution of types of incidents for the two ethnoracial groups. In general these were similar, and the largest difference occurred in the categories of "gossip/jokes," where the proportion was higher for the All Other group and "mild verbal," where the proportion was higher for the White group. More importantly, these numbers may not fully capture the impact of racist comments, behaviours, or attitudes. Although respondents made few comments explicitly about racism, those that were reported were disturbing and warrant further attention and consideration. For example, one female student said, "The experience that had the most impact on my life was when I was told to shut the F up and to take off my paki diaper which in this girl's eyes meant the hijab." 
Disability. The proportions of students who reported that they have a disability were as follows: $1.6 \%$ physical, 4.6\% learning, 3.3\% psychiatric, $6.2 \%$ visual, $0.8 \%$ hearing, $0.3 \%$ culturally deaf, and 1.8\% other disability. For each type of disability, individual two-way ANOVAs of impact scores with sex of respondent and disability (yes or no) as independent variables were performed. Significantly higher impact scores were found for individuals who reported a Learning Disability, $F(1,600)=7.77, p<.01, M_{\text {disability }} 2.69, M_{n o-\text { disability }}=2.16$, and Psychiatric Disability, $F(1,600)=12.35, p<.01, M_{\text {disability }} 2.89, M_{n o-d i s a b i l i t y}=2.16$.

\section{Impact on Academic Work}

To assess the differences among the categories of negative experiences on students' academic performance, a one-way ANOVA was performed for type of incident with impact on academic work as the dependent variable. The test revealed significant differences in the mean impact of different type of incidents, $F(18,566)=6.37, p<.001$. As can be seen in Figure 2, the "policy rules" category $(\mathrm{M}=3.33)$ had the highest mean impact on academic work followed by the "sexual assault/rape" category $(M=3.15)$. Tukey HSD posthoc tests revealed that the "policy rules" category had a significantly higher impact on academic work than all other categories except the "sexual assault/rape," "happened earlier," "noise disruption," and "stalking" categories. Also, the category "sexual assault/rape" had a significantly higher impact than phone/computer, theft, other sexual incidents, mild physical, horseplay, and gossip/jokes.

Figure 2. Impact on academic work mean by category of negative social experience.

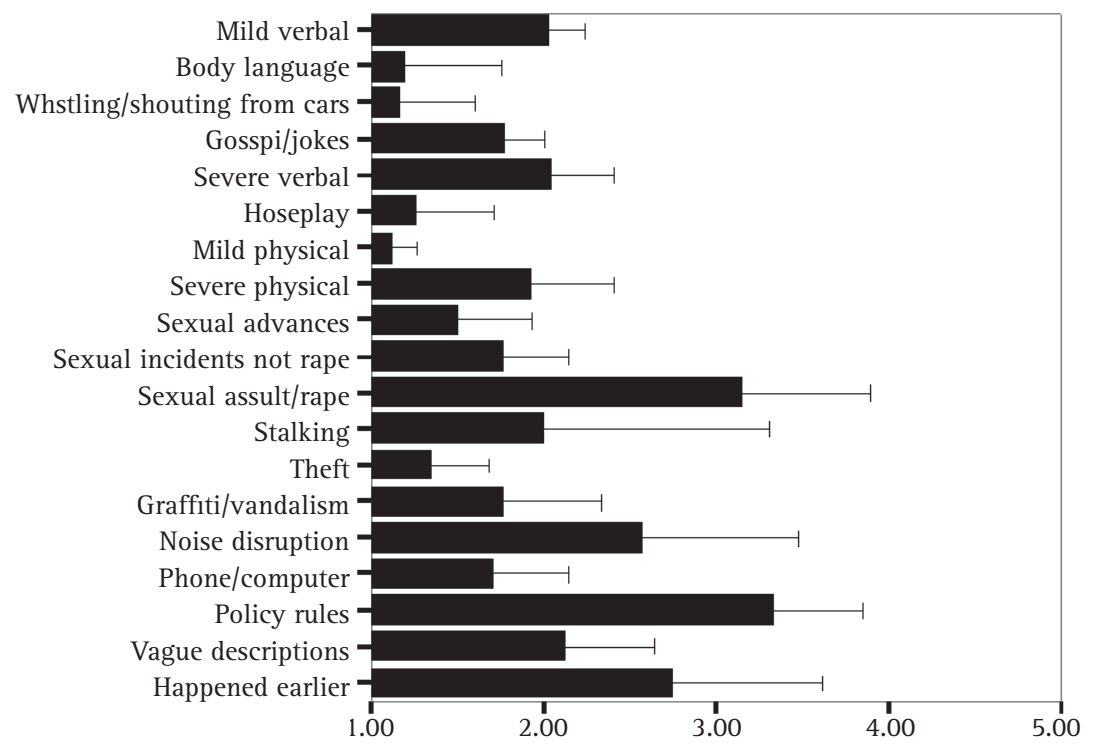

Error bars show the 95th percent confidence intervals. $1=$ no impact; $2=$ little impact; $3=$ moderate impact; 4 = large impact; 5 = very large impact. 
It should not be construed that incidences which fell outside of the "sexual assault/rape" category were without consequence. Although it is not possible to state with certainty whether or not offensive comments, attitudes, or behaviours had a direct impact on academic performance, the qualitative data enable us to glean important insights. More specifically, disturbing comments from several students regarding the climate within the classroom are insightful and useful to consider in this regard.

I can write off the instructor as he is an asshole to the entire class ... not just me, but the classmate, who is in her late 40s, should be forced to take part in a campus wide religious tolerance program as she is just as bad toward the Muslims in my class as well. She talks out loud in the classroom about them rotting in hell as well, straight to their faces, when they are wearing headcoverings and I know this upsets her to the nth degree.

Several students described comments by professors as their most disturbing experience. One spoke about discriminatory comments toward students with disabilities, stating "the most serious was the discrimination from the professor and the seeming ignorance of some of [the university's] administration staff regarding the needs of students with disabilities." Another university student told of being yelled at and belittled by a professor.

I was yelled at by a professor in from of a class of approximately 150 . He yelled at me, belittled me, singled me out in front of a lot of people, embarrassed, and insulted me. The worst thing he said was, 'I'm going to kill you'. He was obviously enraged and out of control.

Concerns regarding inappropriate behaviour, unwanted attention, and the misuse of positions of authority on the part of professors were heard by several respondents. One student remarked, "the experience with the professor was the most serious to me because he was in a position of authority and used it to essentially make fun of me." Similarly, another student explained that her most distressful incident was "the TA asking me to pose for pictures wearing a small dress and riding a bicycle." It is noteworthy that all of these comments were reported by female students. Although we are not able to ascertain the direct impact of these statements, they suggest that students encounter a range of undesired, unsolicited, and unpleasant experiences within the classroom and at the very least, warrant further scholarly consideration.

\section{DISCUSSION}

Although various studies have documented incidents of harassment, aggression, and violence experienced by university and college students, the approach taken in the present study was to assess a broad range of negative social experiences and to explore the impact of these experiences on students' emotional 
state and their academic work. Our approach revealed that, for this sample of Canadian college and university students, nearly two thirds of women and half of men have had some experience with unwanted negative social incidents. The majority of these experiences were verbal rather than physical in nature and, according to the students, had relatively little impact on them, emotionally or academically. Overall, then, during their postsecondary experience, most of the students' negative interpersonal encounters appear to have been quite mild.

Despite this reassuring result, it is clear that not all students have been so fortunate. Some report having been quite seriously affected by the incidents they described, even when they have had what may appear to be relatively benign experiences involving, for example, "mild" verbal abuse where the overall impact of such events on most respondents in the study was low. In addition, even though the total number of students who reported experiencing serious violence, such as sexual assault/rape, was low (2.7\% of all females), such events have had a significant impact on their lives, as have events reported in the category "happened earlier," such as prior sexual assaults or being abused during childhood.

The men and women who participated in this study reported experiencing certain kinds of negative experiences in similar proportions, including mild verbal abuse, gossip/jokes, and theft. However, all of the sexually-related experiences were reported by women, as well as nearly all of the mild physical incidents, which consisted largely of "grabbing" incidents. Female students also reported significantly higher impact scores for the severe physical category of incidents than did the male students. For male-reported incidents in this category, the majority of opponents were other men (83.3\%) and for female-reported incidents, $63.2 \%$ of the perpetrators were men (similar to results reported by Tremblay, Graham, \& Jelley, 2005).

Female students who lived by themselves had significantly higher impact scores associated with negative social experiences than female students who were living in a college or university residence. This difference may be due to a greater sense of vulnerability felt by women who are living alone and who may not have as much access to supportive relationships. Students with learning disabilities or psychiatric disabilities also reported a higher impact of the incidents than other students. The mean impact score was lower for students in the White category than students in the other group consisting of a combination of all other ethnoracial groups. This result is not surprising given reports of negative experiences based on ethnicity and race. More research is needed on the influence of ethnoracial differences and disabilities on the prevalence and impact of negative social experiences among college and university students.

With respect to academic work, students reported a moderate impact of negative social experiences in the categories of policy rules, sexual assault/ rape, events that occurred earlier, and noise disruption. Negative experiences labelled as "policy rules" included perceived unfair workload, grades, classroom regulations, administrative difficulties, and conflicts between professors 
or teaching assistants and students. These results are particularly important in light of findings that uncivil behaviour is associated with perceptions of social ostracism and interactional injustice which can in turn have various negative consequences including a negative impact on cognitive abilities (Barker Casa \& Cortina, 2007).

The low rate of response (15.7\%) is a limitation of this study, and we suspect that many students who were invited to participate may have decided not to respond if they did not have a negative social experience to report. The main implication of this low response rate is that the present study does not provide a precise estimate of the prevalence of negative social experiences on campus. As well, it is possible that the use of a computer-based survey may have dissuaded some from participating. Although this approach affords a greater degree of anonymity than more traditional pen and paper survey questionnaires or faceto-face interviews, it is also possible that some students were reluctant to share deeply personal experiences in such a seemingly impersonal manner. However, the present study provides a detailed picture of the types of interpersonal conflict situations that arise among students and provides a useful first step in developing a classification of these experiences.

Contrary to a popular perception of violence as a present-absent phenomenon, the findings from this research support the notion that negative social acts are present in multiple forms and, while shooting outbreaks on college campuses may grab the headlines, it is clear that negative social experiences experienced by students occur along a broad continuum, weighted by degrees of hostility and the relative social costs of acknowledging or ignoring them. Female students are particularly likely to be negatively affected by these experiences, even by those we might consider to be relatively "mild" in form. This finding is consistent with results reported in high school and preschool populations (see Berman, McKenna, Traher Arnold, MacQuarrie, \& Taylor, 2000; Crick, Casas \& Ku, 1999) where unwanted social experiences including verbal abuse and harassment may contribute to a diminished sense of self, feelings of guilt and shame, particularly among girls who may believe that they are somehow responsible for the offensive behaviour.

For those concerned with keeping college and university campuses safe, it is clear that students can be affected by a broad range of negative social experiences, some of which have a significant impact of their emotional wellbeing and academic performance. Programs focusing on prevention of sexual assault and violence against women should remain a priority, as should support services for people living with the aftermath of such experiences, including those which have occurred prior to their arrival on campus. However, although it is important to focus on more severe forms of violence, this study also highlights the importance of recognizing and providing supports to students who are exposed to other types of negative social experiences. One of the challenges in effective institutional response is to create a context wherein students can recognize and name the problem, a process that is complicated by the relatively amorphous, 
subtle, and insidious nature of unwanted social events. To address the varied forms of negative social experiences that students commonly encounter, rather than to suggest that seemingly mild incidences are without consequence, a prudent institutional response may be to acknowledge that the effects of these experiences are often subtle and insidious, and may last long after the offense has occurred. In addition, institutions should anticipate and educate students about interpersonal conflict rather than merely reacting after the fact. Although most universities and colleges have sexual harassment policies in place, these need to be routinely reviewed and revised to ensure that they provide the requisite degree of safety students need and have the necessary depth and breadth to encompass a wide range of situations. Commonly employed punitive responses, including discipline, dismissal, and legal action, may be useful in the short term. However, these approaches contribute to a perception that such incidents are isolated problems between individuals and are generally ineffective in their capacity to bring about lasting change at a deeper structural or systemic level. The latter, which requires a serious examination of the social climate on university and college campuses, is more difficult to achieve and requires a substantial commitment on the part of campus administrators.

\section{NOTES}

1 It should be noted that the categories "Flirting" and "Self harm" were not included because they only had one respondent each. The category "Happened to someone else" was also omitted in this analysis because it referred to incidents not experienced by the respondent.

2 Note that the lack of statistical difference between the highest mean of 2.63 (living with children) and the mean in other categories was due to low sample size.

3 In order to control for the increase in Type 1 error associated with performing 22 tests, we used a conservative alpha value of .01. Only two other categories were significant at the .05 level: "Noise disruption" and "Happened to someone else" with higher proportions in the college sample).

\section{REFERENCES}

Adlaf, E. M., Demers, A., and Gliksman, L. (Eds.) (2005). Canadian campus survey 2004. Toronto, Centre for Addiction and Mental Health.

Aosved, A. C., \& Long, P. J. (2005). College women's experiences of psychological maltreatment and sexual assault. Violence and Victims, 20, 577-587.

Berman, H., McKenna, K., Traher Arnold, C., MacQuarrie, B., \& Taylor, G. (2000). Sexual harassment: Everyday violence in the lives of girls and women. Advances in Nursing Science, 22(4), 32-46.

Barker Caza, B., \& Cortina, L. M. (2007). From insult to injury: Explaining the impact of incivility. Basic and Applied Social Psychology, 29, 335-350. 
Brush, L. D. (2000). Battering, traumatic stress, and welfare-to-work transition. Violence Against Women, 6, 1039-1065.

Crick, N. R., Casas, J. F., \& Ku, H. C. (1999). Relational and physical forms of peer victimization in preschool. Developmental Psychology, 35(2), 376-385.

DeKeseredy, W. \& Kelly, K. (1993). The incidence and prevalence of woman abuse in Canadian university and college dating relationships. Canadian Journal of Sociology, 18(2), 137-159.

Fisher, B. S., Cullen, F. T., \& Turner, M. G. (2000). The sexual victimization of college women. Washington, DC: U.S. Department of Justice, Office of Justice Programs, National Institute of Justice.

Graham, K., Tremblay, P. F., Wells, S., Pernanen, K., Purcell, J., \& Jelley, J. (2006). Harm, intent and the nature of aggressive behavior of males and females: Measuring aggression in the real world based on observations of barroom behavior. Assessment, 13, 280-296.

Gross, A. M., Winslett, A., Roberts, M., \& Gohm, C. L. (2006). An examination of sexual violence against college women. Violence Against Women, 12, 288-300.

Harris, M. B. (1992). Sex, race and experiences of aggression. Aggressive Behavior, 18, 201-217.

Horsman, J. (1999). Too scared to learn: Women, violence and education. Toronto, ON: McGilligan Books.

Jones, S. L. (2000). Sexual assault on campus. Dissertation Abstracts International, 60(8-B). 4228. (UMI No. 9945421).

Leonard, K. E., Quigley, B. M., \& Collins, R. L. (2002). Physical aggression in the lives of young adults. Prevalence, location, and severity among college and community samples. Journal of Interpersonal Violence, 17, 533-550.

Luckey, R. H. (1999). A study of interpersonal violence among college students living on campus. Dissertation Abstracts International, 60(4-A), 1042. (UMI No. 9928064).

Mellin, E. A. (2004). An examination of the ability of gender, relational victimization, and rejection sensitivity to predict level and subjective experience of depression. Dissertation Abstracts International, 64(9-A), 3203. (UMI No. 3103835).

Raphael, J. (1996). Prisoners of abuse: Domestic violence and welfare receipt. A second report of the Women, Welfare, and Abuse Project. A Taylor Institute report. Chicago, IL.

Shonk, S. M., \& Cicchetti, D. 2001. Maltreatment, competency deficits, and risk for academic and behavioral maladjustment. Developmental Psychology, 37(1), 3-17. 
Tremblay, P. F., Graham, K., \& Wells, S. (2008). Severity of physical aggression reported by university students: A test of the interaction between trait aggression and alcohol consumption. Personality and Individual Differences, 45, 3-9.

Tremblay, P. F., Graham, K., \& Jelley, J. (May 2005) Experiences of physical aggression among university students. Organized poster symposia presented at the $13^{\text {th }}$ Annual Meeting of the Society for Prevention Research, Washington.

Wechsler, H., Lee, J. E., Kuo, M., \& Lee, H. (2000). College binge drinking in the 1990s: A continuing problem: Results of the Harvard School of Public Health 1999 College Alcohol Study. Journal of American College Health, 48, 199-210.

\section{ACKNOWLEDGEMENT}

This study was supported by a Scotiabank Community Grant from the Centre for Research and Education on Violence Against Women and Children. We thank Stephanie Howe and Melissa Snell for coding the incidents, and Sarah Brennek for her suggestions regarding this manuscript.

\section{CONTACT INFORMATION}

Paul F. Tremblay

Centre for Addiction and Mental Health

100 Collip Circle, Suite 200

London, Ontario, Canada, N6G 4X

ptrembla@uwo.ca.

Paul F. Tremblay is a Scientist in the Social, Prevention, and Health Policy Research Department at the Centre for Addiction and Mental Health, an Adjunct Research Professor in the Psychology Department at The University of Western Ontario, and an Academic Research Associate at the Centre for Research and Education on Violence Against Women and Children in London, Ontario. He is currently overseeing a CIHR funded diary-longitudinal study investigating alcohol consumption patterns, depressive symptoms, and experiences of conflict and aggression in a university student sample.

Roma Harris is a Professor in the Faculty of Information and Media Studies at The University of Western Ontario. Her current research is focused on health help-seeking in rural communities. She is leading the 'Rural HIV/AIDS Information Networks Project' funded by the Canadian Institutes of Health Research and she is also co-editor with Nadine Wathen and Sally Wyatt of the recently released book, Mediating Health Information: The Go-Betweens in a Changing Socio-Technical Landscape, published by Palgrave MacMillan. 
Helene Berman is Associate Professor of Nursing at the University of Western Ontario and Scotiabank Research Chair, Centre for Research and Education on Violence Against Women and Children. Her research focuses on the intersections among culture, health, and violence in the lives of children and she has led several national studies related to subtle and explicit forms of violence experienced by girls and young women. She is past Chairperson of the Alliance of Canadian Research Centres on Violence and co-editor of In the Best Interests of the Girl Child. Dr. Berman's research has been supported by the Canadian Institutes of Health Research (CIHR), Status of Women Canada, and the Social Sciences and Humanities Research Council (SSHRC).

Barb MacQuarrie is the Community Director at The Centre for Research on Violence against Women and Children. She has been an advocate for survivors of violence and has worked on diverse fronts to give voice to their experiences of violence as well as their experiences in the systems that are intended to respond to this violence. She is interested in how research can inform prevention and responses to violence against women and girls.

Gail E. Hutchinson is the Director of Student Development Services at The University of Western Ontario, adjunct professor in the Psychology Department and the Faculty of Education and founding member and research associate for the Centre for Research and Education on Violence Against Women and Children. Research interests include the relationship between childhood trauma and adult psychological functioning.

Mary Ann Smith is a Professor in the Social Service Worker program at Fanshawe College London, Ontario. She is a past advisory board member at the Centre for Research and Education on Violence Against Women and Children. Currently she is a participant in Youth Justice Circles and a Community Team member for the Community Services Coordination Network Wraparound Initiative.

Susan Braley was a Professor of women's studies at the University of Western Ontario, and was a member of the Board for the Centre for Research and Education on Violence against Women and Children in London, Ontario. She also taught English literature and women's studies at Fanshawe College in London. She is now a full-time writer in Victoria, BC.

Jennifer Jelley is currently a health information specialist with the Prince Edward Island Department of Health. Previously, she served as a research associate in the Social, Prevention, and Health Policy Research Department at the Centre for Addiction and Mental Health.

Kristen Dearlove completed an Honors BA in Psychology at King's University College in London Ontario and is currently pursuing a Law Degree at the University of Western Ontario. 